\title{
(PRÉ) CONCEITOS NO ENSINO CRÍTICO DE INGLÊS PARA CRIANÇAS: UM ESTUDO SOBRE O DESENVOLVIMENTO CONCEITUAL
}

\author{
(Pre) Concepts in the critical English teaching to children: a study about \\ conceptual development
}

Déborah Caroline Cardoso PEREIRA Universidade Estadual do Oeste do Paraná deborahccp@hotmail.com https://orcid.org/0000-0002-7221-840X

\begin{abstract}
RESUMO: Abordagens críticas no ensino aprendizagem de línguas e na formação docente, bem como o ensino de língua inglesa para crianças (LIC) têm sido foco de estudos mundialmente. Com o intuito de unir essas duas áreas e promover um ensino crítico de LIC, foi desenvolvido um projeto de formação inicial de professores/as que atuavam na rede municipal de ensino em Apucarana (PR). O objetivo desta pesquisa é investigar o processo de desenvolvimento do conceito de ensino crítico de LIC no mencionado contexto. Para isso, discorro no capítulo teórico-metodológico acerca do desenvolvimento conceitual (VYGOTSKY, 2007; 2008) e da teoria da argumentação (LIBERALI, 2013) utilizados na análise linguística. Os dados analisados são provenientes dos encontros do projeto supracitado e explicitados na seção metodológica. Nas considerações finais retomo o processo de desenvolvimento conceitual e concluo que, neste contexto, se desenvolveu um pseudoconceito de ensino crítico de LIC, cujo sentido está relacionado a uma ferramenta para problematizar e evitar a propagação de (pré) conceitos. Como contribuição, é notável a relevância de um grupo multicultural de professores/as para uma formação conceitual significativa, assim como o equilíbrio entre fontes conceituais espontâneas e científicas. PALAVRAS-CHAVE: Formação Docente Crítica; Desenvolvimento conceitual; Ensino de Inglês para Crianças.
\end{abstract}

\begin{abstract}
Critical approaches to language learning and teaching and teacher education, as well as teaching English language to children have been the focus of studies worldwide. In order to connect these two areas and promote critical teaching of English to children, a project for initial education of teachers who worked in the local school system in Apucarana (PR) was developed. The objective of this research is to in-
\end{abstract}

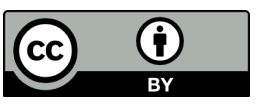


vestigate the process of development of the concept of critical teaching of English to children in the mentioned context. For this, I address the theoretical-methodological chapter about conceptual development (VYGOTSKY, 2007; 2008) and the theory of argumentation (LIBERALI, 2013) used in the linguistic analysis. The analyzed data emerges from the meetings of the aforementioned and explained in the methodological section project. In the final considerations, I resume the conceptual development process and conclude that, in this context, a pseudoconcept of critical teaching of English to children was developed, whose meaning is related to a tool to problematize and prevent the propagation of (pre) concepts. As a contribution, the relevance of a multicultural group of teachers for a meaningful conceptual formation is remarkable, as well as the balance between spontaneous and scientific conceptual sources. KEY-WORDS: Critical Teacher Education; Conceptual Development; Teaching English to Children.

\section{INTRODUÇÃO}

$\mathrm{Na}$ atualidade, o processo de ensino aprendizagem de línguas e a formação docente baseados em perspectivas críticas estão em voga. É necessário, no entanto, compreendermos que existem diversas definições de ensino/perspectiva/abordagem crítica (FREITAS; PESSOA, 2014; FAIRCLOUGH, 2010; COTS, 2006; PENNYCOOK, 2001; LEWIS et al, 2014) e, por essa razão, professores/as e pesquisadores/as podem adotar diferentes versões deste ensino, com diferentes nomenclaturas ${ }^{1}$.

Ao trabalharmos com o ensino de língua inglesa nas séries iniciais temos ainda outras demandas e especificidades. Assim, qual ou/e como seria um ensino crítico de Língua Inglesa para Crianças (LIC)? Desenvolver um conceito, como este, é um processo social que varia de acordo com o contexto sócio-cultural-histórico (SMAGORINSKY, 2013).

Em outras palavras, ao tratarmos de conceitos sociais ${ }^{2}$ o desenvolvimento de um conceito específico depende de variadas nuances, como o contexto, as condições de produção, os/as participantes envolvidos/as, suas realidades sociais, econômicas, culturais.

Diante da complexidade da formação conceitual de um ensino crítico de LIC, bem como da formação docente, desenvolvi em 2016, na Universidade Estadual do

\footnotetext{
${ }^{1}$ Tais como: pedagogia decolonial, abordagem reflexiva, perspectivas críticas.

2 Definir conceitos biológicos, o conceito de uma borboleta, por exemplo, mesmo com possibilidades de reformulações de novas espécies, é mais simples do que pensar a respeito de definições sobre conceitos sociais, como o conceito de ensino efetivo (SMAGORINSKY, 2013). 
Paraná (Unespar), um projeto de extensão cujo objetivo era promover práticas críticas de ensino aprendizagem de LIC nas escolas municipais de Apucarana (PR).

As dinâmicas do projeto incluíam discussões das práticas educacionais realizadas com as crianças, bem como leitura e discussão de textos acadêmicos referentes a essa temática. Assim, refletíamos acerca do ensino crítico de LIC enquanto conceito científico e espontâneo, como proposto por Vygotsky $(2007,2008)$.

O objetivo deste estudo ${ }^{3}$ é investigar o processo de desenvolvimento do conceito de ensino crítico de LIC neste contexto em questão. Para fins de análise, desenvolvi um processo de codificação colaborativa dos dados (SMAGORINSKY, 2008), o qual me possibilitou mapear os conceitos em uso e suas fontes (VYGOTSKY, 2007; 2008). Posteriormente, analisei as pistas linguístico-discursivas segundo a teoria da argumentação (LIBERALI, 2013), o que permitiu compreender a construção conceitual por meio da linguagem.

Como contribuições desta pesquisa, concluo que, ainda que não tenha ocorrido o desenvolvimento de um conceito genuíno ${ }^{4}$, e sim de pseudoconceitos, o trabalho realizado por pessoas de diferentes realidades socioculturais tornou o processo de desenvolvimento conceitual bastante significativo e democrático. Juntos, desenvolvemos o sentido de ensino crítico de LIC como ferramenta para problematizar e evitar a propagação de (pré) conceitos.

Também pude notar a relevância das relações dialéticas entre o conhecimento colocado de maneira institucionalizada (conceitos científicos) e aqueles estabelecidos por cada um, informal e cotidianamente (conceitos espontâneos), ou seja, os resultados desta pesquisa reforçam a importância já dada por Vygotsky (2008) ao equilíbrio entre conceitos espontâneos e científicos numa formação conceitual significativa.

No intuito de melhor orientar a leitura deste texto, o organizei em 4 tópicos, quais sejam: 1 Referencial teórico-metodológico (espaço para considerações teóricas e metodológicas acerca do desenvolvimento conceitual e da teoria da argumentação); 2 Metodologia (uma descrição do projeto que originou esta pesquisa); 3 Análise dos dados (onde examino os excertos provenientes dos encontros do grupo); e 4 Considerações finais.

\footnotetext{
${ }^{3}$ Este artigo é derivado da minha tese de doutoramento.

${ }^{4}$ Um conceito genuíno é entendido como aquele completo, estabelecido. 


\section{REFERENCIAL TEÓRICO-METODOLÓGICO}

Neste tópico, discutirei o arcabouço teórico-metodológico que suporta a análise dos dados deste estudo, como já mencionado, os pressupostos Vygotskianos (VYGOTSKY, 2008; 2007) em relação ao desenvolvimento conceitual, e a teoria da argumentação, segundo Liberali (2013).

\subsection{Desenvolvimento de (pré) conceitos}

Desde o momento em que nascemos, passamos a conhecer, aprender e nos desenvolver por meio de interações sociais e biológicas da vida humana. Com o passar dos anos, iniciamos a jornada escolar e o contato com instrumentos e materiais específicos para nos ensinarem, como livros didáticos voltados à alfabetização. Aprendemos, portanto, por meio das interações sociais e também por teorias específicas de ensino e aprendizagem.

Segundo Vygotsky (2008), a aprendizagem informal, que ocorre por meio de experiências e contatos sociais, culmina no desenvolvimento dos chamados conceitos cotidianos ou espontâneos ${ }^{5}$. Por conseguinte, o conhecimento aprendido em contextos formais, voltados para a formação específica e teórica, é nomeado conceito científico.

Um conceito, de maneira geral,

é mais do que a soma de certas conexões associativas formadas pela memória, é mais do que um simples hábito mental; é um ato real e complexo de pensamento que não pode ser ensinado por meio de treinamento (VYGOTSKY, 2008, p.104).

Dito de outra maneira, conceitos não podem ser transferidos de um para o outro, como na chamada educação bancária (FREIRE, 1987), segundo a qual o professor "deposita" o conhecimento em seus alunos. Conceitos implicam no desenvolvimento de funções intelectuais, tais como "atenção deliberada, memória, lógica, abstração, capacidade de comparar e diferenciar" (VYGOTSKY, 2008).

Mesmo sendo conceituados de maneiras distintas e polarizadas, porque se desenvolvem em direções opostas (AZEVEDO, 2016), os conceitos cotidianos e científicos possuem uma relação dialética. O primeiro autor explica que "o desenvolvimento dos conceitos espontâneos [...] é ascendente, enquanto o

\footnotetext{
${ }^{5}$ Conceitos cotidianos e conceitos espontâneos são entendidos como sinônimos.
} 
desenvolvimento dos conceitos científicos é descendente, para um nível mais elementar e concreto" (VIGOTSKY, 2008, p.135).

O pesquisador conclui que conceitos científicos e espontâneos, inicialmente afastados por suas naturezas distintas, terminam por se encontrar, culminando na formação de um conceito em si. Daí a relevância de ambas fontes conceituais, científica e espontânea, para o desenvolvimento de um conceito genuíno.

Ademais, em seus estudos, Vygotsky (2008) identificou dois ${ }^{6}$ tipos de generalizações ou fases básicas na trajetória até a formação de conceitos, visto que ainda não atingem uma unidade teórica: complexos e pseudoconceitos. Ambos dizem respeito aos conceitos científicos e espontâneos.

No estágio de desenvolvimento do entendimento complexo, "objetos isolados associam-se na mente" (VYGOTSKY, 2008, p. 76), ou seja, alguns membros de determinada organização podem estar unificados com outros, mas não estão unificados de acordo com o mesmo princípio. A exemplo da criança que identifica tudo que voa como um inseto, até mesmo um avião, ou aquela que identifica todo animal de quatro patas como um cachorro (SMAGORINSKY, 2013).

A forma mais elevada de um complexo no desenvolvimento conceitual (VYGOTSKY, 2008) é nomeada pseudoconceito. Nesta fase, os membros de um conjunto aparecem unificados, mas possuem inconsistências internas. Smagorinsky (2013) usa a metáfora de Vygotsky para explicar que um pseudoconceito é a sombra de um conceito, pois já apresenta seus contornos. Os elementos de um determinado grupo parecem estar unidos, mas há contradições, como a criança que passa a diferenciar pássaros de morcegos, apesar de ambos voarem.

Vygotsky (2008) esclarece que o pseudoconceito é formado por uma semelhança concreta visível e/ou um processo de associação, assim, o resultado pode ser idêntico a de um pensamento conceitual, porém o processo de desenvolvimento não é o mesmo. Para o pesquisador, o pseudoconceito pode servir como um "[...] elo de ligação entre o pensamento por complexos e o pensamento por conceitos. É dual por natureza: um complexo já carrega a semente que fará germinar um conceito" (VYGOTSKY, 2008, p.85).

Apesar do foco de Vygotsky estar no desenvolvimento infantil, os estágios de desenvolvimento dos conceitos não são exclusivos às crianças, mas podem ser observados

\footnotetext{
${ }^{6}$ Ao estudar o desenvolvimento conceitual infantil, Vygotsky (2008) propõe três fases básicas anteriores ao conceito em si: 1) agregação desorganizada ou amontoados sincréticos, 2) complexo e 3) pseudoconceito. Neste estudo, faço uso dos pressupostos vygotskyanos relacionando-os à formação docente, por esta razão, ocupo-me apenas dos dois últimos como Smagorinsky et al (2003; 2013).
} 
também em adultos quando iniciam uma nova atividade, como os professores em suas práticas docentes (SMAGORINSKY, 2013). Dessa forma, podemos dizer que a maneira como desenvolvemos determinado conceito também é social e cultural, portanto, ideológica.

Ao basear-se em Vygotsky, Smagorinsky (2013) explica que o desenvolvimento do conceito não segue um trajeto linear (complexo, pseudoconceito e conceito) e sim twisting ${ }^{7}$. O pesquisador acredita que quando se trata de cursos de formação para professores/as, esse ir e vir no desenvolvimento conceitual é influenciado por diversos fatores, entre eles, a dicotomia entre conhecimentos da universidade e da escola.

Para investigar os mecanismos linguístico-discursivos presentes nos excertos, faço uso da teoria da argumentação (LIBERALI; FUGA, 2014; LIBERALI, 2013), pois como afirma Smagorinsky (2013), Vygotsky investiga os processos pelos quais as pessoas desenvolvem conceitos por meio de articulações baseadas no discurso e em outras formas de mediação cultural. Além disso, também corroboro com Azevedo (2016, p. 81), o qual afirma que:

Vygotsky (2000 [1934]) não especifica que aspectos/domínios da linguagem estão diretamente envolvidos na formação de conceitos, o que me leva a crer que a linguagem como um todo, como capacidade simbólica do sujeito, contribua ativa e efetivamente nesse processo.

Assim, no tópico a seguir explanarei sobre a teoria da argumentação utilizada neste estudo.

\subsection{Linguagem como mediadora da formação conceitual}

A proposta de Liberali (2013) para investigação da argumentação, em contextos de sala de aula, é uma perspectiva dialógica e interdependente, porém organizada em categorias, a saber: características enunciativas, discursivas e linguísticas.

\footnotetext{
${ }^{7}$ Twisting pode ser traduzido como cheio de curvas, com mudanças de direção.
} 
Após o trabalho de recorte e organização dos dados, apoio-me nas características discursivas e linguísticas para o desenvolvimento da minha análise ${ }^{8}$. As características discursivas da argumentação

são compreendidas a partir de quatro aspectos centrais com relação ao modo como o texto pode ser disposto: 1) o plano organizacional; 2) a organização temática; 3) o foco sequencial e; 4) a articulação entre as ideias apresentadas ${ }^{9}$ (LIBERALI, 2013, p. 66).

O plano organizacional compreende como o enunciado se inicia, desenvolve e encerra (LIBERALI; FUGA, 2014; LIBERALI, 2013). É importante constatar como os interactantes iniciam o diálogo, pois isso pode "decidir o tipo de relação que será a base para o desenvolvimento da reunião" (LIBERALI, 2013).

No que se refere à organização temática, a investigação se ocupa com o tema, se o que foi proposto é ou não pertinente, se obteve continuidade ou não, por meio das dimensões: desenvolvimento e pertinência.

Pontecorvo et al (2005 apud LIBERALI, 2013) explica que a dimensão do desenvolvimento está relacionada ao avanço na definição do objeto proposto, por meio de uma participação coletiva, com introdução e discussão de novas perspectivas. Enquanto o não-desenvolvimento, como o nome propõe, refere-se ao "bloqueio ou interrupção do processo de construção das ideias pelo enunciador ou grupo", "a dimensão de pertinência oferece base para a percepção se o tema proposto foi seguido ou desviado, comprometendo a progressão (ou não) do discurso" (LIBERALI, 2013, p.67).

O foco sequencial, segundo Liberali (2013), está relacionado à escolha do tema em discussão. Por esta razão, esta categoria discursiva foi abordada já na seleção e também no recorte dos dados, visto que os excertos analisados possuem a mesma temática: entendimentos e tentativas de ensino crítico de LIC. Assim, não haverá, na análise dos dados, relatos utilitários e instrucionais, como orienta a mesma autora, como avisos, cobranças, compartilhamento de materiais, entre outros, que também faziam parte das discussões do grupo.

\footnotetext{
${ }^{8}$ As características enunciativas não compõem o quadro analítico deste estudo, pois como explica Liberali (2013, p. 61-62), tais categorias "não são aplicáveis de forma mecânica [mas sim uma] "contribuição para a criação de novas bases". Tendo em vista que a categoria enunciativa focaliza o contexto da interação (local, momento, participantes, objetivos e papéis dos participantes), optei por apresentar tais aspectos como parte do desenvolvimento metodológico desta pesquisa, e não como categoria de análise.

${ }^{9}$ Esta última também chamada de articulação argumentativa (LIBERALI; FUGA, 2014).

Revista X, v. 16, n. 3, p. 664-686, 2021. 
No entanto, Liberali (2013) explica que a tematização pode "assumir um caráter mais prático e voltado ao conhecimento cotidiano ou mais teórico e/ou científico" (VYGOTSKY, [1934] 2000 apud LIBERALI, 2013, p.68). Como o objetivo desta análise é verificar o processo de desenvolvimento de conceitos espontâneos e científicos, observarei, segundo o foco sequencial proposto pela autora mencionada anteriormente , se os efeitos de sentidos causados nos/pelos interlocutores são de origem conceitual prático/cotidiano ou teórico/científico.

Por fim, a articulação discursiva argumentativa se ocupa da "forma como ideias, posições, pontos de vista são apresentados, contrastados, sustentados, acordados" (LIBERALI, 2013, p. 68). A autora explica como fazer uma análise segundo a articulação discursiva argumentativa:

É fundamental perceber se os modos de articulação se estruturam de forma simples (como breves respostas ou colocações) ou elaboradas (de formas mais complexas e longas). Na sequência, é preciso considerar a função que ocupam na articulação discursiva" (LIBERALI, 2013, p. 68).

Tais funções são organizadas em 13 categorias: 1) abertura do tema ou exórdio; 2) questão controversa; 3) apresentação de pontos de vista/tese; 4) espelhamento, recolocação do que foi apresentado; 5) espelhamento com pedido de dis/concordância; 6) concordância com ponto de vista; 7) discordância/contestação do ponto de vista; 8) negação/ refutação de argumento; 9) acordo ou síntese; 10) pedido/ apresentação de esclarecimento; 11) pedido/ apresentação de contra-argumentação; 12) questões para entrelaçamento de falas, modos de questionar; 13) pedido, apresentação de sustentação (LIBERALI, 2013, p. 68).

As características linguísticas da argumentação, por sua vez, estão organizadas em oito mecanismos linguísticos, quais sejam: 1) Mecanismos conversacionais; 2) Mecanismos de coesão verbal; 3) Mecanismos lexicais; 4) Mecanismos de coesão nominal; 5) Mecanismos de valoração; 6) Mecanismos de distribuição das vozes; 7) Mecanismos de modalização; 8) Mecanismos de interrogação.

A autora denomina esses mecanismos de composição do discurso como "aspectos da materialidade do texto". Na seção metodológica adiante, apresentarei o projeto de extensão que foi contexto da realização desta pesquisa. 


\section{METODOLOGIA}

\subsection{O projeto de extensão}

No atual cenário político educacional brasileiro, a educação infantil e o ensino nas séries iniciais estão sob responsabilidade dos governos municipais. Assim, cabe às prefeituras ofertar e regulamentar esse ensino. Em Apucarana, essa oferta foi inicialmente discutida em 2013 e teve início no ano de 2014, em caráter de projeto. Atualmente, todas as 37 escolas municipais oferecem aulas regulares de inglês. Os alunos contemplados frequentam desde o maternal, até o término do ensino fundamental I.

O corpo docente está divido de maneira equilibrada entre professores efetivos do Município, professores contratados via Processo Seletivo Simplificado (PSS) e professores estagiários, alunos do curso de Letras-Inglês, Letras-Espanhol e pedagogia da Universidade Estadual do Paraná (Unespar), campus Apucarana.

Em 2016, dei início ao projeto de extensão intitulado Teaching to play or playing to teach ${ }^{10}$ Um projeto de formação crítico-colaborativa de professores de inglês para crianças, cujos objetivos gerais eram: i) auxiliar no processo de ensino-aprendizagem de inglês para crianças; ii) oferecer apoio teórico-pedagógico e linguístico aos/às professores/as em formação inicial; iii) oportunizar uma formação crítico-colaborativa aos acadêmicos.

Quanto aos objetivos específicos, tínhamos: i) ler e refletir acerca da formação crítico-colaborativa de professores de inglês, bem como do ensino de inglês para crianças; ii) desenvolver material didático para o ensino de inglês para crianças, ancorado nos pressupostos teóricos e orientações curriculares que subjazem este contexto; iii) aliar teoria e prática para contribuir com o processo de ensino-aprendizagem de inglês críticocolaborativo da professora formadora em formação, professores em formação e os estudantes da rede municipal; iv) contribuir com a formação inicial dos/as professores/as por meio da solução de problemas, planejamento de aulas e planos de aula, organização de material, relacionamento com a comunidade escolar, etc; v) promover um trabalho docente crítico-colaborativo por meio de grupos de estudo.

Os grupos de estudo eram embasados em leituras de textos que abordassem teorias crítico-colaborativas de formação docente e do processo de ensino-aprendizagem de inglês para crianças. Inicialmente, os encontros foram divididos em duas etapas: primeiro, os/as professores/as em formação apresentavam o levantamento semanal

\footnotetext{
${ }^{10}$ Ensinar a brincar ou brincar para ensinar?

Revista X, v. 16, n. 3, p. 664-686, 2021.
} 
de suas aulas (possíveis dilemas, efetividade das atividades, situações da sala de aula, conflitos, soluções), uma vez que a formação crítico-colaborativa parte do pressuposto da necessidade do diálogo, do questionamento, da argumentação, do crescimento junto com o outro, por isso a importância deste momento.

Em um segundo momento, fazíamos discussões dos textos acadêmicos. Em cada encontro, um membro do grupo era responsável pela seleção do material que seria lido e pela condução da discussão, pois na formação colaborativa, além dos papéis e responsabilidades serem intercambiáveis, é a partir da interação com o outro que compreendemos e constituímos a nós mesmos (MATEUS et al, 2013).

Os/as cinco participantes do projeto eram acadêmicos do curso de Letras-Inglês (Joana, Isabel, João, Nicolas e Catarina ${ }^{11}$ ). Catarina, uma jovem de 27 anos, estava no último ano do curso de graduação, por esta razão já havia realizado dois anos consecutivos de estágio obrigatório, tanto no ensino fundamental II, como no ensino médio, em escolas da rede pública de ensino também em Apucarana, demonstrando, portanto, experiência em sala de aula.

Após três meses lecionando nas escolas municipais, Catarina optou por trabalhar como professora em uma escola estadual, por meio do PSS. Por esta razão, sua participação no projeto e na constituição dos dados deste trabalho foram sucintas.

Joana e Isabel são irmãs, com 28 e 26 anos de idade respectivamente. Possuíam diploma universitário em design de moda. Joana ainda contava com a formação em gestão de negócios. Ambas estavam no segundo ano de graduação e lecionavam inglês para crianças pela primeira vez. Isabel começou seu estágio fora das salas de aula, como monitora, auxiliando nos corredores e pátio. As duas não concluíram o ano letivo de 2016, porque Isabel decidiu se dedicar a sua primeira formação superior como designer e Joana teve problemas de saúde que a afastaram do estágio. Posteriormente, ela também iniciou outra ocupação profissional.

João é o único aluno que começou a dar aulas neste contexto um ano antes do início do projeto (2015). Foi o único também que deu continuidade no ano seguinte (2017). Em 2016, atuou com crianças nas escolas municipais e cumpriu com o seu estágio obrigatório no ensino fundamental II.

${ }^{11}$ Os/as participantes preencheram um termo de consentimento livre esclarecido (TCLE) concordando em ter suas falas gravadas, transcritas e analisadas, bem como com a alteração de seus nomes para nomes fictícios. Vale elucidar que os compromissos éticos desta pesquisa foram garantidos pelo TCLE. Como já mencionado, este artigo é parte da minha tese de doutorado (defendida em 2019), a qual não foi submetida ao Comitê de Ética da Plataforma Brasil. 
Nicolas participou ativamente, no entanto, acabou desistindo do curso de graduação e, consequentemente, do projeto. João e Nicolas eram da mesma turma e cursavam o terceiro ano da graduação.

Tendo discorrido sobre os caminhos teórico-metodológicos, bem como sobre o contexto da realização da pesquisa, a seguir, apresentarei a análise dos dados.

\section{ANÁLISE DOS DADOS}

Como já explicitado, buscávamos no projeto desenvolver práticas críticas de ensino de LIC. E as falas que serão analisadas a seguir foram mapeadas durante o processo de decodificação colaborativa dos dados ${ }^{12}$ (SMAGORINSKY, 2008).

No excerto adiante, João narra sua experiência na aula de Linguística Aplicada, cujo foco era no ensino de inglês para crianças. Ele explica que, depois de ler e discutir alguns materiais com seus colegas e a professora da disciplina, todos/as os/as professores/as em formação deveriam representar uma aula com este foco. Eles não tinham exigências desta professora de incluir perspectivas críticas à aula, porém João prontamente considerou isto.

Logo no início do encontro do dia 26 de abril, João se manifestou da seguinte maneira:

Excerto 1: Datado em 26 de abril de 2016.

8. João - Como eu tinha pouco tempo, eu não consegui trabalhar com a parte crítica, porque eu trabalhei sobre família em inglês. Aí eu falei o vocabulário, trabalhei a fala em inglês, entreguei exercício, trouxe imagens. Aí na parte que eu ia trabalhar, criticamente, sobre a família, sobre várias, diversos tipos de famílias que nós temos hoje na sociedade [...] Mas não trabalhei, claro, porque tinha, gente estava até apressando.

9. Déborah - Sim, é! Às vezes, a gente fica engessado nas estruturas que a gente tem: tempo, currículo, material didático. Mas, então, você acha que, por exemplo, esse tema família, pra gente trabalhar ele criticamente, seria, sei lá, conscientizar essas crianças de que família não é pai, mães, filhinhos, ou não? Não sei. Não sei.

${ }^{12} \mathrm{O}$ processo de codificação colaborativa dos dados (SMAGORINSKY, 2008) consiste em analisar sistematicamente seus recortes usando o ATLAS.ti, um software de análise de dados de pesquisas qualitativas. Em parceria com Smagorinsky, lemos e discutimos todos os excertos selecionados e "chegamos a um acordo sobre cada código por meio de discussão colaborativa ao invés de corroboração independente" (SMAGORINSKY, 2008, p.401, tradução minha).

Revista X, v. 16, n. 3, p. 664-686, 2021. 
Inicialmente, cabe evidenciar a presença do conceito agir docente, que teve maior ocorrência ${ }^{13}$ (34\%) no processo de codificação colaborativa dos dados. Isto quer dizer que, para os/as professores/as em formação, o próprio trabalho docente é essencial para o desenvolvimento do conceito de ensino crítico de LIC; é recorrente, também, o subcódigo professores podem prevenir ou perpetuar estereótipos e intolerância.

Os mecanismos de distribuição de vozes presentes neste excerto, pelo uso pronominal do a gente, ao invés de eu, indica minha aproximação ao trabalho realizado pelos/as professores/as em formação, em sala de aula, uma vez que não atuo diretamente com o ensino de LIC. Com isso, compreendo que o desenvolvimento do trabalho crítico com as crianças é uma ação em conjunto.

Também faço uso dos mecanismos de modalização, não sei, não sei, abrindo espaço para que os alunos façam suas colocações sem impor a minha opinião ou dizer que tal atitude é correta ou equivocada. Coloco-me num papel coadjuvante, ao afirmar que não sei como seria este trabalho, porém de protagonismo em relação ao desenvolvimento dos questionamentos.

Em sua prática argumentativa, João faz uso da conjunção porque duas vezes. Ambas podem ser consideradas mecanismos de coesão nominal entre argumentos "com expansão de significados uma vez que a argumentação prossegue com explicações" (TANACA, 2017, p. 160). Neste caso, podemos destacar as razões pelas quais João não optou por ensinar criticamente: i) necessidade de trabalhar sobre o tema família em LI; ii) tempo. João fez uma distinção entre o ensino de inglês (vocabulário, pronúncia) e o ensino crítico (discutir diferentes tipos de família).

Professores/as e pesquisadores/as que atuam por um viés crítico, em sua maioria, não trabalham com o processo de ensino-aprendizagem de línguas para crianças, da mesma forma, os profissionais do ensino de LIC parecem se dedicar a outras questões, também pertinentes, como: materiais didáticos (MACHADO, 2008), ensino e aprendizagem de vocabulário (SCAFFARO, 2010); saberes docentes (TUTIDA, 2016), entre outros.

Por outro lado, pesquisas como a de São Pedro ${ }^{14}$ (2016) parecem indicar uma tendência de união entre essas áreas. São Pedro (2016, p.17) defende que o ensino de LIC seja realizado por um viés crítico, "para que se ampliem modos de ser, fazer e dizer,

\footnotetext{
${ }^{13}$ Parte do processo de codificação colaborativa dos dados é o levantamento do percentual da reincidência dos conceitos mapeados.

${ }^{14}$ O objetivo da tese de doutoramento de São Pedro (2016) é "observar e avaliar as bases e oportunidades para um trabalho orientado pela ideia de transdisciplinaridade e de formação cidadã no processo de ensino-aprendizagem de língua inglesa no EFI." (SÃO PEDRO, 2016, p. 20).
}

Revista X, v. 16, n. 3, p. 664-686, 2021. 
[...] para que o mundo seja um lugar mais justo para todos". Para a pesquisadora, esse modo de educar é também uma orientação ética.

Posteriormente, o professor em formação João fez uma contribuição ao apresentar uma maneira possível de como os/as professores/as podem se preparar para trabalhar com momentos críticos ${ }^{15}$ :

Excerto 2: Datado em 26 de abril de 2016.

10. Nicolas - Não, mostrar...é...o que que a sociedade mostra que é família, por exemplo, dois homens e uma criança, duas mulheres e uma criança, mais ou menos isso, tipo assim, sobre as diversas famílias que nós temos.

11. Déborah - Sim, que duas mulheres formam uma família tanto quanto um homem e uma mulher.

12. João. Isso! Daí surge um pouco de discussão na sociedade de se isso é família ou não.

13. Déborah - Entendi.

14. João - Então, talvez a gente pode fazer uma discussão com as crianças, ver o que que elas acham sobre isso.

Neste enunciado, tanto as modalizações de Nicolas, mais ou menos isso, tipo assim, como as de João, talvez a gente pode, funcionam como possibilidades de ações pedagógicas. Estávamos juntos discutindo caminhos para se trabalhar criticamente. Corroboro com Liberali (2013, p. 82) que "a análise e uso cuidadoso desses mecanismos [de modalização] podem contribuir na constituição de uma cultura de colaboração crítica", ou seja, a não imposição de ideias dentro do grupo indica um exercício de colaboração.

A prática argumentativa presente neste excerto também é marcada por expressões de concordância, tanto na minha fala $(\operatorname{sim})$, quanto na fala de João com um tom exclamativo enfático por meio da expressão coloquial: Isso! A manutenção do tema levantado por João (nos dois recortes apresentados) permite inferir que, em relação à organização temática (ibidem), o tema (discussão sobre tipos de família) foi pertinente para a definição do objeto proposto (ensino crítico de LIC) de maneira coletiva.

15 Momentos críticos são "momentos quando aproveitamos a oportunidade para fazer algo diferente, quando percebemos que estamos desenvolvendo um novo entendimento [...] quando alguma coisa muda, onde alguém "percebe", onde alguém faz um comentário que muda o discurso? Uma questão difícil para todos os professores é como conseguir capturar aqueles momentos de transformações em potencial e torná-los em momentos críticos (PENNYCOOK, 2004, p. 330). Ou seja, momentos inesperados e não planejados. 
Além dos possíveis momentos críticos $^{16}$, podemos compreender nesta análise que é possível realizar o ensino crítico de LIC também por meio de atividades préestabelecidas, mas que provoquem o diálogo.

Nicolas responde ao meu questionamento afirmando que um ensino crítico de LIC (também) é questionar o que a sociedade mostra que é família. Para João, trabalhar criticamente é apresentar diversos tipos de família que nós temos hoje na sociedade, a partir de uma discussão com as crianças, a fim de verificar o que que elas acham sobre isso, o que culminará na discussão na sociedade se isso é família ou não.

Como teorizado por Vygotsky (2007) conceitos são produtos e produtores do social, afinal, "um conceito existe antes de existir para o indivíduo" (DELLAGNELO et al, 2015, p. 53). Ao afirmar que a discussão sobre famílias, dentro da sala de aula, pode gerar um diálogo sobre as diferentes famílias na sociedade, João e Nicolas estão contribuindo com a legitimação dos conceitos, de modo que estejam em constante desenvolvimento, visto que este processo de apropriação de novos conceitos/conhecimentos ocorre nas relações entre os sujeitos, em determinado ambiente sócio-histórico.

O conceito de família é oriundo de um processo de internalização (VYGOTSKY, 2007), em que a família (ainda) é social, cultural e historicamente constituída por um casal heterossexual (que idealmente namoraram, casaram, tiveram filhos). No entanto, essa concepção é passível de ser (e está sendo) reeditada por intermédio da interação humana.

É possível compreender também que o conceito de família, cuja ocorrência no processo de codificação colaborativa dos dados equivale a $13 \%$ de toda referência conceitual durante as reuniões do grupo, é claramente representado pelo subcódigo suposições conservadoras sobre estrutura familiar. E que os/as professores/as em formação acreditam que o conceito família seja relevante na tentativa de ensino crítico de LIC.

Além do conceito de família, as falas discutidas neste excerto indicam o uso do conceito $L G B T Q+$ inclusão/exclusão (ocorrência de 26\%) para fundamentar a formação

\footnotetext{
${ }^{16}$ Apesar de ter descrito o que faria, ou seja, que teria planejado previamente sua atividade, fator que não caracteriza este ensino crítico como uma abordagem por meio de momentos críticos, João acrescentou que dai surge um pouco de discussão na sociedade de se isso é família ou não. Como professor daquelas crianças, ele sabia quais problemáticas os alunos poderiam trazer de suas casas para a sala de aula. Portanto, ainda que os momentos críticos sejam não-planejados, depois de certo tempo, os professores conhecem seus alunos e as possíveis reações às situações e tópicos em discussão. Os professores não podem prever momentos críticos, por outro lado, ao proverem e serem providos de uma educação crítica, professores e formadores podem aprender a lidar com incidentes críticos a fim de reduzir preconceitos, estereótipos e contribuir com o desenvolvimento de cidadãos críticos.
} 
conceitual de ensino crítico de LIC, por meio do subcódigo: Casais homossexuais podem ser pais de família.

João ${ }^{17}$, em outro momento, começa a discorrer sobre sua aula a respeito das cores, por meio do plano organizacional de abertura (LIBERALI, 2013). Joana o interrompe para enfatizar a possibilidade de ensinar também sobre racismo. Então, o colega imediatamente acrescenta que já havia feito isso antes. Ambos acreditam ter potencializado aqueles momentos à criticidade, uma vez que ajudaram seus alunos a repensarem o conceito a respeito da cor da pele. Os/as professores/as em formação afirmam (por meio da categoria discursiva de concordância de ponto de vista) que costumavam ensinar sobre racismo.

Excerto 3: Datado em 17 de maio de 2016.

226. João - No primeiro ano quando eu fui ensinar as cores, eu fui tentar falar um pouquinho assim sobre a importância das cores.

227. Joana - Nossa, mas dava pra você ensinar sobre racismo.

228. Nicolas - É, e também como...

229. João - Ah? Mas eu faço isso direto (estalos de dedo).

230. Joana - Lápis de cor de pele.

231. Nicolas - Cor de rosa é cor de menina e azul é cor de menino.

$[\ldots]$

238. Déborah - Então, e vocês acham que a gente se preocupar em buscar essas opções de ensinar cor, é esse ensino crítico ou é só sei lá, outra coisa?

239. Nicolas - Daí, ó nesse, nesse é, com esse tema você pode aborda preconceito racial, preconceito, ai como que eu posso falar?! De, de sexualidade, não, não é sexualidade, é sexualidade?! Porque daí, porque nas cores você já vê desde pequeno que, o que é, é cor de menino e cor de menina. [...] E mostrar que tudo é cores, entendeu?! Acho que a gente tem que tentar abrir a cabeça do aluno, sabe?!

240. Déborah - E a nossa, né?!

241. Nicolas - Sim.

Para os/as professores/as em formação inicial, ensinar as cores em LI pode desencadear discussões sobre preconceitos raciais (cor de pele) e também de gênero

${ }^{17}$ João é o professor em formação negro que levantou questões de raça no projeto. Ele também foi o único que iniciou seu trabalho com crianças anteriormente ao projeto, finalizou o ano letivo e continuou no ano subsequente. 
(cor de menino e cor de menina). Ambos constituem conceitos elencados no processo de codificação dos dados: $L G B T Q+$ (26\% de ocorrência) e racismo (15\% de ocorrência).

A argumentação usada pelo professor em formação Nicolas é constituída de sentido implícito, uma vez que ele faz uso de uma expressão coloquial e metafórica (TANACA, 2017): abrir a cabeça do aluno. Para ele, o entendimento de ensino crítico de LIC está relacionado ao acesso às diferentes referências externas, significa dizer que, como professores, precisamos criar oportunidades para que os alunos possam ressignificar entendimentos.

Quando eu afirmo, através da linguagem metafórica (abrir a nossa cabeça), indico que também precisamos repensar nossos próprios pressupostos, porque o trabalho com o ensino crítico é, dentre tantos outros aspectos, colocar em cheque crenças e valores que temos e exercemos como professores. Para garantir concordância com esse posicionamento, faço uso de um questionamento coloquial (né), em busca de uma concordância coletiva, que é prontamente respondido por Nicolas.

Em outro encontro, Joana chamou a atenção para dois fatores: i) todos precisamos aprender criticamente; ii) ensino crítico age para além de um indivíduo.

Excerto 4: Datado em 14 de junho de 2016.

158. Joana - quem tem que ser ensinado não é só a criança, o que tem que ser mudado, tem que ser mudado igual a um vírus assim, joga um vírus, e a criança pega e a outra pega, outro pega, outro pega.

159. Déborah - Eu também acho.

Joana parece concordar com a minha preocupação em transpor o ensino crítico para além das crianças, estendendo-o para nós. Ela também materializa o ensino crítico enquanto conscientização, ao compará-lo, através de uma metáfora, com um vírus, algo que desencadeia efeitos, desde que tenha havido contato.

Neste excerto, é possível identificar novamente o conceito agir docente na fala de Joana, tem que ser ensinado, bem como é inferida sua crença de que na forma de um vírus que age e transforma, o ensino proporciona mudança: tem quer ser mudado.

Joana amplia seu entendimento de ensino crítico como conscientização: 
Excerto 5: Datado no dia 14 de junho de 2016.

182. Joana - Então, eu acho que na maior parte do tempo que a gente fala de ensino crítico a gente fala da falta de valor. Do que ensino crítico, não sei se isso tá atrelado. Falta de valor humano.

183. Déborah - Não entendi, falta de valor?

184. Joana - Porque toda vez que a gente fala alguma coisa assim, é sobre falta de educação ou é falta de conscientização, mas na maioria das vezes é falta de valores, sabe aqueles valores que a gente aprendia?! De educação.

185. Isabel - Então, mas essa coisa de o professor tá lá em cima e os alunos lá embaixo e tudo que o professor diz você tem que falar "Amém" e a criança nem raciocina sobre isso é uma coisa, é um valor antigo, sabe?!

186. Joana - Mas eu estou falando de valor humano, sabe?! Igualdade.

Carregado de carga emotiva, identificado pelas escolhas lexicais: falta de valores, falta de valor humano, igualdade, os turnos da professora em formação Joana também são marcados por mecanismos de modalização: eu acho, não se, que indicam incerteza em sua fala. Ela parece repetir o mesmo argumento referente à igualdade de cor (em relação à raça e gênero), mas dessa vez, ampliando suas bases, indicando as ausências: falta de valor humano. Para ela, se faltam valores humanos, falta igualdade. Assim, o ensino crítico de LIC não se trata apenas de ensinar cores, mas valores.

Os elementos de ligação nessa argumentação são as escolhas lexicais (educação) e verbais (que a gente aprendia) de Joana, que indicam a relação que a professora em formação faz entre o ensino (oriundo da educação) e a igualdade. Podemos notar, através do tempo verbal conjugado no passado (aprendia) que, para ela, atualmente, isto não ocorre mais.

Tais colocações estão relacionadas ao conceito de agir docente. Fica evidente neste excerto o entendimento do subcódigo professores podem prevenir ou perpetuar estereótipos e intolerância. Se a educação pode promover igualdade, os/as professores/as possuem papel relevante na perpetuação ou prevenção de preconceitos.

Nesse momento, vale retomar as contribuições de Kalantzis e Cope (2000) acerca da linha tênue entre uma educação que ascende o indivíduo financeira e socialmente e os resultados deste processo, que acabam por excluir ainda mais os menos privilegiados. Consequentemente, cabe reforçar a contribuição social da oferta do ensino de LIC de qualidade nas escolas públicas brasileiras, como possibilidade de superação de tamanha desigualdade (SÃO PEDRO, 2016). A mesma autora (2016, p.26) explica ainda que a 
realidade [do ensino de inglês] brasileira é pensada por Copland e Garton (2014) ao afirmar que, no México e em países da América do Sul, o reconhecimento de que o ensino de inglês traz tanto desvantagens quanto benefícios em termos sociais levou a uma abordagem crítica para o ensino de inglês, até mesmo no caso das crianças.

No encalço do que afirma a autora, a tentativa do desenvolvimento de um ensino crítico de LIC desse grupo vai ao encontro do entendimento que este ensino pode contribuir, como também desfavorecer os indivíduos.

A colocação de Isabel, professor está lá em cima e os alunos estão lá embaixo e tudo que o professor diz você tem que falar "Amém”, diz respeito aos subcódigos respeito deveria ser mútuo entre professores e alunos; poder dos professores em relação aos alunos. Assim, ao discutirmos sobre a efetividade no ensino crítico relacionado à indisciplina, tivemos o seguinte diálogo:

Excerto 6: Datado em 28 de junho de 2016.

44. Catarina - A gente tenta falar as coisas pra conscientizar, mas entra aqui e sai aqui.

45. Joana - Não se conscientiza, sabe também por que não conscientiza? Porque é muitos termos que a gente usa, eles não entendem, sabe? Eu tento, às vezes, eu falo...

46. Catarina - Tem vezes que eles perguntam “O que é isso?”.

47. Joana - Eles não sabem as palavras.

48. Catarina - Aham.

49. Joana - Você tem que usar as palavras, assim...

50. Catarina - Eu falei assim "Ajam como pessoas civilizadas". Aí, perguntou "o que é isso, civilizada?".

51. Joana - É, eles não sabem.

A abertura do tema realizada por Catarina é marcada por sua concepção com relação ao objetivo do ensino crítico de LIC e também do papel do professor, o de conscientizar (A gente tenta falar as coisas pra conscientizar), seguida por sua argumentação metafórica (mas entra aqui e sai aqui) que conota um tom de desabafo relacionado a não eficácia de seu trabalho docente, identificado também pela escolha verbal: tentar.

Por meio da categoria discursiva de organização temática proposta por Liberali (2013), é possível notar que Joana dá continuidade ao tema por meio da dimensão de 
desenvolvimento. A professora em formação amplia o diálogo que trata da tentativa de conscientização. Vale ressaltar que o foco sequencial neste excerto diz respeito ao conhecimento espontâneo, experienciado pelos participantes em suas práticas. Fator relacionado ao processo de codificação colaborativa dos dados no qual identificamos que $46.8 \%$ de toda fonte conceitual das discussões era espontânea.

Ao relatarem que os alunos não atendem determinadas instruções por não as compreendem, é possível refletir sobre duas questões: i) linguagem como mediadora de desenvolvimento; ii) falta de conhecimento teórico ${ }^{18}$ acerca da aprendizagem infantil.

A primeira problemática reforça os pressupostos vygotskyanos que relacionam linguagem e desenvolvimento. As crianças ainda não passaram pelo processo de internalização de determinados conceitos (usados pelas professoras em formação) e, por esta razão, sem a compreensão da linguagem (que atua como instrumento mediador do desenvolvimento), não houve aprendizagem.

Tendo em vista a perspectiva sociointeracionista, Tutida (2016) defende que Vygotsky contribui “com [a] discussão sobre os papéis a serem desempenhados por professores de LIC" ( Ibidem, p. 78), indicando o papel de mediador da aprendizagem. Suas escolhas linguísticas, portanto, são fundamentais e devem fazer sentido naquele ambiente infantil.

No que diz respeito à segunda questão, é consenso entre pesquisadores da área (TANACA, 2017; TUTIDA, 2016; CRISTÓVÃO; GAMERO, 2009; SANTOS; BENEDETTI, 2009) que existem saberes específicos para o ensino de línguas para crianças. Daí a relevância de uma formação diferenciada para professores que atuam ou desejam atuar no ensino de LIC.

Catarina e Joana narram que eles não entendem, eles não sabem, eles perguntam "O que é isso?" As professoras em formação perceberam a importância do papel da linguagem utilizada com as crianças, apenas quando inseridas neste contexto. Por isso a relevância da contribuição de Tutida (ibidem) de que o/a professor/a que atua com o ensino de LIC deve ter conhecimento sobre o desenvolvimento cognitivo e social das crianças, de maneira apropriada para cada faixa etária ${ }^{19}$, bem como o domínio de teorias e metodologias de ensino de línguas. A pesquisadora defende que esse conhecimento deve anteceder a prática, "pois os alunos influenciam totalmente o trabalho docente e, por isso, não se pode desconsiderar os alunos e as interações como variáveis que integram esse trabalho" (TUTIDA, 2016, p. 76).

\footnotetext{
${ }^{18}$ Aqui cabe lembrar que apenas $14.2 \%$ da fonte conceitual dos dados é científica.

${ }^{19}$ Além de considerar as individualidades dos aprendizes. 
No entanto, neste contexto, como em muitos outros cursos de formação de professores/as, isto não ocorre. Os/as professores/as em formação tiveram a oportunidade de ensinar inglês para as crianças das escolas municipais de Apucarana, por meio de estágio não obrigatório, sem formação específica anterior.

Em suma, ao observarmos o sentido construído de ensino crítico de LIC enquanto problematização de preconceitos, notamos também a incapacidade de realização de um trabalho eficaz, devido à ausência de conhecimento teórico acerca da educação infantil que poderia ter acontecido anterior e concomitantemente à prática.

\section{CONSIDERAÇÕES FINAIS}

$\mathrm{Na}$ seção introdutória desta pesquisa, levantei o seguinte questionamento: qual ou/e como seria um ensino crítico de LIC? Como um conceito em constante desenvolvimento, não seria possível apresentar uma resposta única e finita. Nesta pesquisa específica, no entanto, foi possível notar que o sentido de ensino crítico de LIC está relacionado a problematizar e evitar a propagação de preconceitos.

Conceitos são construções sociais desenvolvidos por meio da linguagem (SMAGORINSKY, 2013) e preconceitos são, antes de tudo, conceitos ou (pré) conceitos, em estágio de pseudoconceitos e/ou complexos, haja vista sua precariedade de conformidade e definição. Assim, eles se moldam e modificam conforme nossas ações individuais e sociais. Se concordamos que existe preconceito dentro da sala de aula, como evidenciado nos registros linguísticos apresentados na análise dos dados, e que a educação, por meio de um ensino crítico, é um caminho para superá-los ou perpetuá-los, devemos nos tornar conscientemente responsáveis, enquanto professores/ as, pela linguagem que mediará nossas aulas. Afinal, a linguagem cria não somente (pré) conceitos, mas também nossa realidade social.

Em seu livro Para educar crianças feministas, Chimamanda Adichie (2017, p.35) nos aconselha a ensinar as crianças a questionarem a linguagem: "a linguagem é o repositório de nossos preconceitos, de nossas crenças, de nossos pressupostos. Mas, para the ensinar isso, você terá que questionar sua própria linguagem". Tal afirmação vai ao encontro dos pressupostos vygotskyanos sobre a relevância das nossas escolhas linguísticas, inclusive e principalmente no ambiente infantil.

Ademais, nesta pesquisa, tivemos um grupo diversificado de professores/as, o que gerou desenvolvimento conceitual mais democrático e significativo, pois diferentes pontos de vista, realidades, desafios e prioridades foram expostos e discutidos. Essa foi a 
riqueza deste grupo multicultura ${ }^{20}$ de professores/as, cujas discussões se transformaram em possibilidades de perspectivas de ensino através de uma postura crítica.

\section{REFERÊNCIAS}

ADICHIE, C. N. Para Educar Crianças Feministas: Um Manifesto. São Paulo: Companhia das Letras, 2017.

AZEVEDO, T. D. Argumentação: subsídio para a formação de conceitos científicos. In.: LIBERALI, F.; DAMIANOVIC, M. C.; NININ, M. O. G.; MATEUS, E. F.; GUERRA, M. (Orgs.). Argumentação em contexto escolar: relatos de pesquisa. Campinas: Pontes Editores, 2016. p. 81-109.

COTS, J. M. Teaching 'with an attitude': critical Discourse Analysis in EFL Teaching. ELT Journal, v.60, n.4, p. 336-345, oct, 2006.

CRISTÓVÃO, V. L. L.;GAMERO, R. Brincar aprendendo ou aprender brincando? O inglês na infância. Trabalhos em Linguística Aplicada. [online], vol.48, n.2, p. 229-245, 2009 .

DELLAGNELO, A. de C. K; SILVA, L.; ROCHA, N. V. Para além do conceito cotidiano: a concepção de atividades de ensino-aprendizagem com vistas à (re)conceitualização de apresentações acadêmicas. Brazilian English Language Teaching Journal. Porto Alegre, v. 6, sp. n. - suppl., p. 50-61, dez, 2015.

FAIRCLOUGH, N. Critical discourse analysis: the critical study of language. Harlow: Pearson Education Limited, 2010 [1995].

FREIRE, P. Pedagogia do oprimido. 17 ed. Rio de Janeiro: Paz e Terra, 1987.

FREITAS, M. T. de U.; PESSOA, R. R. Discursos de identidades, ensino crítico de línguas e mudança social: análise de uma experiência localizada. In: MATEUS, E.; OLIVEIRA, N. B. (Orgs.). Estudos Críticos da Linguagem e Formação de Professores/as de Línguas: contribuições teórico-metodológicas. Campinas, SP: Pontes Editores, 2014.

KALANTZIS, M.; COPE, B. Changing the roles of schools. In: COPE, B.; KALANTZIS, M. Multiliteracies: literacy learning and the design of social futures. London: Routledge, 2000, p.121-148.

\footnotetext{
${ }^{20}$ Esta informação também pode nos levar a pensar sobre a importância das políticas de inclusão e permanência nas universidades.

Revista X, v. 16, n. 3, p. 664-686, 2021. 
LEWIS, C.; PYSCHER, T.; STUTELBERG, E. Critical sociocultural perspectives in English education. In: BRASS, J.; WEBB, A. Reclaiming English language arts methods courses: critical issues and challenges for Teacher Educators in Top-Down Times. New York: Routledge, 2014.

LIBERALI, F. Argumentação em contexto escolar. Campinas, SP: Pontes Editores, 2013.

LIBERALI, F.; FUGA, V. P. Argumentação na atividade de formação crítica, colaborativa e criativa. In: MATEUS, E.; OLIVEIRA, N. B. De (Orgs.). Estudos Críticos da Linguagem e Formação de Professores/as de Línguas: contribuições teórico-metodológicas. Campinas, SP: Pontes Editores, 2014.

MACHADO, R. Análise de material didático de língua inglesa voltada para crianças em um contexto de local da rede municipal de ensino. 2008. 244 f. Dissertação (Mestrado em Linguística Aplicada) - Universidade de Brasília. Brasília, 2008.

MATEUS, E.; EL KADRI, M. S.; SILVA, K. A. (Orgs.) Experiências de formação de professores de línguas e o PIBID: contornos, cores e matizes. Campinas, SP: Pontes Editores, 2013.

PENNYCOOK, A. Critical moments in a TESOL praxicum. In: NORTON, B.; TOOHEY, K. Critical Pedagogies and Language Learning. Cambridge: Cambridge University Press, 2004, p. 327-346.

Critical Applied Linguistics: A Critical Introduction. Mahwah, NJ: Lawrence Erlbaum, 2001.

SANTOS, L. I. S; BENEDETTI, A. M. Professor de língua estrangeira para crianças: conhecimentos teórico-metodológicos desejados. Trabalhos em Linguística Aplicada. Campinas, v.48, n.2, p.333-351, jul./dez, 2009.

SÃO PEDRO, J. de. Lingua inglesa, transculturalidade e transdisciplinaridade no ensino fundamental I: percursos e representações docentes. 2016. 281 fls. Tese (Doutorado em Estudos da Linguagem) - Universidade Estadual de Campinas, Campinas, 2016.

SCAFFARO, A. P. O uso da atividade de contar histórias como recurso na retenção de vocabulário novo na língua inglesa com crianças na fase pré-escolar. In: ROCHA, C. H.; TONELli, J. R. A.; SILVA, K. A. (Orgs.) Lingua estrangeira para crianças: ensinoaprendizagem e formação docente. Campinas, SP: Pontes Editores, 2010, p.61-92

SMAGORINSKY, P. The development of social and practical concepts in learning to teach: A synthesis and extension of Vygotsky's conception. Learning, Culture, and Social Interaction, v. 2, n.4, p. 238-248, December, 2013. 
The method section as conceptual epicenter in constructing social science research reports. Written Communication, v.25, n.3, p. 389-411, July, 2008.

TANACA, J. J. C. Aprendizagem expansiva em espaços híbridos de formação continuada de professoras de inglês para crianças no projeto Londrina Global. 2017. $257 \mathrm{f}$. Tese (Doutorado em Estudos da Linguagem) - Universidade Estadual de Londrina. Londrina, Paraná, 2017.

TUTIDA, A. F. Ensino de língua inglesa para crianças: questões sobre formação de professores e os saberes da prática. 2016. 339 fls. Dissertação (Mestrado em Estudos da Linguagem) - Universidade Estadual de Londrina. Londrina, Paraná, 2016.

VYGOTSKY, L. S. A construção do pensamento e da linguagem. São Paulo: Martins Fontes, 2008.

. A formação social da mente. São Paulo: Martins Fontes, [1978] 2007.

Recebido em: 03 jun. 2020

Aceito em: 23 dez. 2020 